https://doi.org/10.34179/revisem.v6i3.13616

\title{
ANÁLISE DE ERROS MATEMÁTICOS DOS ALUNOS DO ENSINO FUNDAMENTAL EM QUESTÕES ENVOLVENDO OS NÚMEROS INTEIROS
}

\author{
ANALYSIS OF MATHEMATICAL ERRORS OF STUDENTS OF \\ FUNDAMENTAL EDUCATION IN ISSUES INVOLVING WHOLE NUMBERS
}

\author{
Sonner Arfux de Figueiredo \\ Universidade Estadual de Mato Grosso do Sul - UEMS \\ sarfux@uems.br \\ Edilson Araújo do Nascimento \\ Secretaria de Educação do Estado de Mato Grosso do Sul - SED \\ edilson_araujonascimento@hotmail.com
}

\begin{abstract}
Resumo
O presente trabalho tem como objetivo analisar os erros cometidos por alunos do ensino fundamental em questões envolvendo os números inteiros e quais contribuições isso traz para o ensino aprendizagem. A pesquisa se desenvolveu em uma escola municipal do inteiro do estado de Mato Grosso do Sul com alunos do $7^{\circ}$ ano do Ensino Fundamental. Essa pesquisa é considerada de natureza quantitativa-qualitativa ou método misto e pesquisas de campo. Por meio da análise de erros foi possível identificar quais os erros cometidos pelos alunos nestes testes e classificá-los de acordo com a tipologia de erros de Brousseau. Os erros foram considerados obstáculos epistemológicos na aprendizagem e para este estudo utilizamos os conceitos de obstáculos na visão de Brousseau. Com esse estudo foi possível identificar os erros mais comuns cometidos pelos alunos, dentre esses destacam as dificuldades na interpretação dos problemas e dificuldades com as operações fundamentais da matemática. Por fim, concluímos que a análise de erro é um instrumento que contribui para a aprendizagem, seja utilizando como método ou como auto avaliação suas potencialidades nos permitem afirmar que a análise passa a ser mais um instrumento eficaz para o ensino e a aprendizagem.
\end{abstract}

Palavras-chave: Análise de Erros; Números Inteiros; Obstáculos Epistemológicos

\begin{abstract}
This paper aims to analyze the mistakes made by elementary school students on issues involving whole numbers and what contributions this brings to teaching and learning. The research was carried out in a municipal school in the entire state of Mato Grosso do Sul with students from the 7 th year of elementary school. This research is considered to be of a quantitative-qualitative nature or mixed method and field research. Through the analysis of errors it was possible to identify which
\end{abstract}


errors were made by students in these tests and to classify them according to Brousseau's typology of errors. Errors were considered epistemological obstacles in learning and for this study we used the concepts of obstacles in Brousseau's view. With this study it was possible to identify the most common mistakes made by the students, among which they highlight the difficulties in the interpretation of the problems and difficulties with the fundamental operations of mathematics. Finally, we conclude that error analysis is an instrument that contributes to learning, whether using its potential as a method or as a self-assessment, it allows us to affirm that analysis becomes another effective instrument for teaching and learning.

Keywords: Error Analysis; Whole Numbers; Epistemological Obstacles Keywords

\section{INTRODUÇÃO}

Neste artigo discutimos como a análise de erros tem sido debatido no campo acadêmico, além de posicionar a análise de erros matemáticos cometidos por alunos em nível de Ensino Fundamental em questões relacionadas aos números inteiros.

Destacamos inicialmente os trabalhos de Cury (2010, p. 02) que define erros na resolução de uma questão matemática como sendo "[...] o que não corresponde à produção esperada de um aluno (ou professor) que já deve ter tido contato com os conteúdos apresentados na referida questão ou com estratégias de resolução de problemas em Matemática". Para a autora, trata-se de uma suposta verdade do conhecimento institucional em que se espera que o aluno (ou professor) apresente em suas produções.

Cury (1990, p. 20) considera que: [...] o aluno errará algumas vezes, mas é a partir destes erros que se dará a construção do conhecimento. Portanto, quando a Matemática é considerada um corpo de conhecimento que se deve ser passado aos alunos, os erros são estigmatizados e só a correção absoluta das respostas é esperada.

Os erros são, para a autora, parte da construção do conhecimento devendo ser considerados pelos professores. Segundo Cury (1990), negar o erro dos alunos em detrimento de uma construção absoluta é condenar o modo como o aluno pensa e constrói suas respostas e o professor que desconsidera o erro do aluno perde uma grande oportunidade de mediar à construção do conhecimento.

A análise de erros, como afirma Cury (2017), é uma tendência na Educação Matemática, visto que muitas pesquisas têm sido direcionadas para esse tema.

As análises dos trabalhos selecionados foram por meio de seus resumos e resultados obtidos, nosso objetivo foi identificar os anos escolares onde se deram as pesquisas, quais conteúdos matemáticos foram estudados e como os erros foram tratados por meio da 
análise de erros e as contribuições que isso trouxe para o ensino e aprendizagem da matemática.

Em sua pesquisa, Brum (2013) analisou os erros cometidos por alunos do $8^{\circ}$ ano na resolução de questões algébricas com o objetivo de identificar os tipos de erros dos alunos e testar uma estratégia de ensino com o uso do software Hot Potatoes ${ }^{1}$.

A autora concluiu em sua pesquisa que é preciso desmistificar a concepção dado ao erro; as respostas dos alunos, mesmo que erradas, trazem informações importantes de como eles usaram determinados conhecimentos na resolução de suas atividades. Dentre o tipo de erro mais identificado pela autora por meio da análise de erros está à manipulação algébrica, especialmente na propriedade distributiva e também nas generalizações. Por meio da intervenção com o software Hot Potatoes, a autora percebeu mudanças significativas no comportamento dos alunos e os erros antes cometidos em atividades realizadas em sala de aula já não ocorreu com o uso desse recurso didático o que, segundo a autora, faz deste instrumento um grande potencial para o ensino de álgebra.

Contudo Vaz (2013) investigou o desempenho de alunos do $7^{\circ}$ Ano relacionados com frações. Em sua dissertação, utilizou de metodologia baseada na análise de soluções propostas pelas autoras Rafaella Borasi e Helena Cury. Por meio de sua pesquisa o autor identificou que os alunos ingressam o $7^{\circ}$ Ano com muitas dificuldades em frações, mas que, por meio de situações debatidas em grupos, fez com que os erros cometidos fossem percebidos e corrigidos em uma segunda atividade. Os resultados obtidos permitiram ao autor concluir que a metodologia didática a partir de uma nova visão dos erros para os envolvidos no processo de ensino aprendizagem precisam de mais investigações, mas que, em seu estudo, apresentou resultados satisfatórios do ponto de vista do estudo com frações.

Já o estudo de Costa (2014) constatou que antes da investigação os erros eram vistos pelos professores como falta de interesse, falta de dedicação e descaso dos alunos e depois da investigação em sua pesquisa eles começaram a buscar compreender quais motivos ou dificuldades encontradas pelos alunos que causam tais fracassos. No estudo o autor investigou em sua tese de doutorado seis professores com o objetivo de identificar como

\footnotetext{
${ }^{1}$ Hot Potatoes é um programa que contém um pacote de seis ferramentas ou programas de autor, desenvolvido pelo Grupo de Pesquisa e Desenvolvimento do Centro de Informática e Média da Universidade de Victoria, Canadá. Fonte: $<<$ http://www.ufrgs.br/redespecial/_doc/guia_hotpotatoes.pdf $>>$. Acesso em $05 / 05 / 2019$ às $18 \mathrm{~h} 41 \mathrm{~min}$.
} 
esses lidam com os erros dos alunos do $6^{\circ}$ Ano do Ensino Fundamental, que perpassou por momentos de observação nas aulas dos professores participantes da pesquisa, bem como nas entrevistas estruturadas realizadas e também nos momentos de formação continuada mediada por ele. Suas observações, houve mudanças no perfil desses professores, ou seja, eles passaram a tratar os erros dos alunos com outro olhar. $\mathrm{O}$ autor ainda observou que, embora os processos de correção dos erros continuassem a serem repetidos em sala de aula, foi perceptível que as indagações antes escassas passaram a ser mais instigadas pelos professores participantes, isso mostra uma preocupação deles em tentar compreender como os alunos pensam quando resolvem as atividades propostas.

Rossato (2014) realizou uma pesquisa de mestrado voltado para análise de erros na divisão de números decimais por alunos do $6^{\circ}$ ano do ensino fundamental. A autora usou como aporte teórico a Teoria da Aprendizagem Significativa de David Ausubel; sua pesquisa teve uma abordagem quanti-qualitativa e os resultados obtidos mostraram que através da análise de erros foi possível identificar os tipos de erros cometidos pelos alunos propiciando a criação de oficinas direcionadas para superação dos erros apurados. Rossato (2014) conclui que a análise de erros é para o ensino aprendizagem um recurso de grande potencial para a prática docente.

Após analisarmos os trabalhos selecionados para a revisão da literatura dessa pesquisa concluímos que os erros têm sido um vigoroso campo de estudo e a análise de erros vem sendo usada como metodologia de pesquisa. Vimos também que muitos conteúdos matemáticos têm sido utilizados nesses estudos, porém, não identificamos a presença de investigações sobre os erros envolvendo os números inteiros; não detectamos trabalhos cuja investigação nos apresente exemplos de obstáculos e erros fundamentados nas teorias de Brousseau $(1997,2008)$ que possa se identificar com nossa questão de pesquisa e, ainda, que evidencie erros cometidos pelos alunos em Matemática que envolva os números inteiros de forma a serem utilizados como meio pedagógico para aprendizagens mais significativas.

Mesmo assim, desta maneira, os resultados das pesquisas que analisamos serviram como aporte importante para a nossa pesquisa à medida que apresentam resultados já consolidados e que auxiliaram em nosso estudo, e a partir destes estudos o que se observa é que muitas das vezes este alerta apresentado pelos alunos através do erro, é 
desconsiderado ou não aproveitado pelos professores para reavaliar suas metodologias com objetivo de compreender o que levou os alunos a terem dificuldades na aprendizagem destes conteúdos, assim desta forma, pretendemos discutir como os erros matemáticos dos alunos podem ajudar os professores a reavaliar seus processos metodológicos com intuito de tornar o ensino e aprendizagem da matemática eficaz.

Contudo o erro é uma variável concomitante ao processo educativo, porque não é possível avançar em um longo e desconhecido caminho sem se equivocar. Dito mais peremptoriamente: não há aprendizagem isenta de erros. A criança erra e erra o adulto, embora menos. É preciso tornar patente este conceito submerso durante múltiplas gerações no currículo oculto. (TORRE, 2007, p.27).

Para o autor não há processo educativo passivo de erro e que esse faz parte da aprendizagem porque é impossível percorrer um caminho longo sem que haja equívocos. Assim é urgente que se reconheça o erro no processo educativo uma vez que por gerações ele esteve submerso no currículo oculto, e a partir destes apontamentos de alguns autores, como Cury (2017) que afirmam que a análise de erros vem se tornando uma tendência no ensino da matemática, seja como metodologia de pesquisa ou metodologia de ensino, evidenciamos nosso objetivo de identificarmos os erros cometidos pelos alunos do ensino fundamental em questões envolvendo os números inteiros, de forma que a análise de erros nos possa permitor também a sua utilização para avaliar o ensino e a aprendizagem matemática em relação ao estudo do conceito de números inteiros.

No tópico que veremos a seguir apresentamos a fundamentação teórica desta pesquisa.

\section{FUNDAMENTAÇÃO TEÓRICA}

O marco teórico que norteará esta pesquisa é fundamentado nas teorias de Guy Brousseau acerca dos obstáculos epistemológicos no ensino aprendizagem da Matemática, observando como se insere sua teoria ao analisarmos os erros matemáticos cometidos por alunos do Ensino Fundamental e como este pode ser utilizado para que os erros possam ser superados no processo de aprendizagem matemática.

Para esta pesquisa será importante a compreensão dos conceitos de obstáculos epistemológicos, visto que os erros cometidos por alunos podem ser considerados como 
obstáculos que precisam ser superados. Diante do exposto, apresentaremos as ideias de obstáculos na construção do conhecimento na visão do pesquisador Brousseau.

Brousseau (2008, p. 49) reconhece que o conceito de obstáculo epistemológico foi introduzido por Bachelard, porém, o autor prefere definir obstáculo de outra maneira:

- Um obstáculo é um "conhecimento" no sentido que lhe demos de "forma regular de considerar um conjunto de situações".

- Tal conhecimento dá resultados corretos ou vantagens observáveis em um determinado contexto, mas revela-se falso ou totalmente inadequado em um contexto novo ou mais amplo.

- O conhecimento novo, verdadeiro ou válido sobre um contexto mais amplo não é determinado "de acordo com" o conhecimento anterior, mas em oposição a ele: utiliza outros pontos de vista, outros métodos etc. Entre eles não existem relações "lógicas" evidentes que permitam desacreditar facilmente o erro antigo por meio do conhecimento novo. Ao contrário, a competição entre eles acontece no primeiro contexto.

- Os conhecimentos aqui considerados não são construções pessoais variáveis, mas, sim, respostas "universais" em contextos precisos. Portanto, surgem quase necessariamente na origem de um saber, seja ela histórica ou didática.

Para o autor, um obstáculo se manisfesta através do erro sendo inútil ignorá-los e sim incorporá-los na maneira de conceber o novo conhecimento, isso está relacionado com o fato de que o obstáculo representa uma maneira de conhecer do sujeito, ele representa um conhecimento que o sujeito traz consigo, podendo não ser o desejável para certo contextos, mas que revela um modo como o sujeito pensa. O obstáculo não desaparece facilmente com as aprendizagens de novos conhecimentos, ele impõe resistência a estes o que irá causar dificuldades no modo de compreender e tais resistências são observadas por meio dos erros, segundo Pinto (2000), “O erro está intrínseco no processo de construção do conhecimento" (p.39).

Brousseau (1997, p. 84) considera que:

Um obstáculo se torna visível pelos erros, mas tais erros não se devem ao acaso. Fugazes, erráticos, são reproduzíveis, persistentes. Além disso, erros cometidos pela mesma pessoa são interligados por uma fonte comum: uma forma de saber; uma concepção característica, coerente se não correta, um "conhecer" anterior que tem sido bem sucedido ao longo de um domínio-ação. Tais erros não são necessariamente explicáveis. O que acontece é que não desaparecem de uma vez; eles resistem, persistem e, então, reaparecem.

Os obstáculos são percebidos pelos erros e estes não ocorrem pelo acaso, ao contrário, apresentam formas de saber do sujeito cognoscente que, mesmo errando, demonstra uma forma de pensar que deve ser explorado e não descartado. Brousseau (1997) ainda sugere que o obstáculo algumas vezes pode ser tão forte que não seja possível 
Figueiredo, S. A.; Nascimento, E. A.

ultrapassá-lo. Para Borasi (1985), a partir da análise dos próprios erros, ou daqueles cometidos por outros, os alunos podem obter uma aprendizagem mais significativa de conteúdos matemáticos. Borasi (1985) e, Cury $(2007,2012)$ defendem o estudo das respostas dos alunos, corretas ou incorretas, para auxiliá-los na construção do conhecimento, de forma que ao analisar nas respostas os erros em atividades e avaliações de matemática dos alunos, podem auxiliar o professor numa melhor compreensão do pensamento matemático, com intuito de buscar metodologias mais adequadas para tornar o ensino aprendizado mais eficaz.

\section{PROCEDIMENTOS METODOLÓGICOS}

A pesquisa foi realizada em uma escola municipal da periferia da cidade de Nova Andradina localizada no Estado de Mato Grosso do Sul. No ano de 2018 essa escola funcionava nos três turnos (matutino, vespertino e noturno). No período matutino tinham 12 salas de Ensino Fundamental - Anos finais, distribuídas em 04 salas de $6^{\circ}$ Ano, 03 salas de $7^{\circ}$ Ano, 03 salas de $8^{\circ}$ Ano e 02 salas de $9^{\circ}$ ano; no período vespertino a escola tinha 11 salas de Ensino Fundamental - Anos iniciais - distribuídas em 01 sala de $1^{\circ}$ Ano, 02 salas de $2^{\circ}$ Ano, 03 salas de $3^{\circ}$ Ano, 02 salas de $4^{\circ}$ Ano e 03 salas de $5^{\circ}$ Ano; e no período noturno funcionava 06 salas da Educação de Jovens e Adultos (EJA) do Ensino Fundamental, distribuídas em 01 sala de Fase I (correspondente a $2^{\circ}$ e $3^{\circ}$ Anos), 01 sala de Fase II (correspondente a $4^{\circ}$ e $5^{\circ}$ Anos), 02 salas de Fase III (correspondente a $6^{\circ}$ e $7^{\circ}$ Anos) e 02 salas de Fase IV (correspondente a $8^{\circ}$ e $9^{\circ}$ Anos).

A escola participa de alguns projetos previstos no Projeto Político Pedagógico (PPP), como: Educação para o Trânsito, Consciência Negra, Meio Ambiente, entre outros; também participa de projetos promovidos pela Secretaria Municipal de Educação em parcerias com outras entidades e órgãos públicos como Festival de Teatro para o Trânsito (Fetran), Agrinho, Festas das Nações, entre outros.

Os participantes desta pesquisa são, em sua maioria, moradores do bairro onde a escola está situada, vindos de famílias carentes e alguns deles não moram com os pais. A turma na qual realizamos a pesquisa é o $7^{\circ} \mathrm{Ano} \mathrm{C}$, ao qual foi considerado para análise os dados de 28 alunos que foram selecionados pelo critério de participar de todos as intervenções na pesquisa. Com o objetivo de levantar alguns dados para essa pesquisa e 
também conhecer um pouco mais sobre esses alunos foi elaborado um questionário e, através desse, pudemos formar um perfil desses alunos. Esse questionário foi aplicado pelo professor e pesquisador durante uma aula de Matemática em horário regular de aula, no período diurno, no final do $3^{\circ}$ e início do $4^{\circ}$ bimestre do ano letivo de 2018 . Ressaltamos que o objetivo desse questionário era saber mais sobre algumas informações pessoais dos alunos e também de aspectos ligados à Matemática e aprendizagem escolar.

Por meio das respostas obtidas do questionário, pode-se formar um perfil dos alunos investigados. A formação desse perfil foi para essa pesquisa relevante, pois permitiu conhecer um pouco mais os alunos investigados e ao mesmo tempo possibilitou obter informações acerca de suas preocupações relativas à Matemática, bem como seus conhecimentos acerca dos números inteiros.

Conforme afirma Hauser (2007, p. 13):

[...] deveria se caracterizar mais como uma passagem dentro de um mesmo nível de ensino do que uma transição propriamente dita, considerando o sentido etimológico dessa palavra. Mas, na prática, o termo que melhor exprime essa passagem é mesmo transição, marcada por uma ruptura que parece ser responsável, entre outras coisas, pela reprovação ou pela evasão escolar.

Para a autora, a transição do Ensino Fundamental Anos Iniciais para o Ensino Fundamental Anos Finais, que deveria ser algo natural por se tratar do mesmo nível de ensino, parece não ser e, mais ainda, provoca rupturas que podem ser uma das causas da reprovação ou evasão escolar. Para o alcance dos objetivos desta pesquisa a metodologia utilizada é de natureza quantitativa-qualitativa ou método misto e pesquisa de campo. A pesquisa de métodos mistos é relativamente nova nas ciências humanas e sociais havendo até algumas discussões entorno de sua validade como técnica, porém, o fato é que muitas pesquisas têm se utilizado desse método para clarificar suas investigações e resultados.

Creswell (2007, p.213) afirma que "vários termos diferentes são usados para essa técnica como integração, síntese, métodos quantitativos e qualitativos, multimodo e multimetodologia, mas que textos recentes usam o termo "métodos mistos"".

O método misto é uma técnica nova que tem provocado muito interesse dos pesquisadores e muitos desses já o reconhece como uma forma válida para compreender problemas de pesquisa. Nesta investigação optou-se por utilizar a pesquisa de campo de forma empírica como forma de obter em locus respostas para o problema de pesquisa. $\mathrm{O}$ tópico a seguir apresentará informações acerca da coleta de dados da pesquisa. 
Devido à pesquisa ter sido desenvolvida com seres humanos, algumas formalidades inerentes tiveram que ser realizadas antes mesmo que as atividades de coleta de dados fossem aplicadas, dentre essas providências destacamos as orientações dadas aos alunos acerca da pesquisa e outras informações que garantisse a todos os participantes a seriedade do nosso trabalho, assim os alunos levaram para suas casas os Termos de Assentimento Livre e Esclarecido (TALE) e o Termo de Consentimento Livre e Esclarecido (TCLE) para preencher com os pais ou responsáveis. Esta pesquisa usou como algumas técnicas para coletar os dados empíricos, como: questionários, entrevistas (individuais), atividades práticas e gravações de áudio. Gil (2008) considera que esta técnica traz grandes contribuições para a pesquisa, pois permite ao pesquisador obter informações do sujeito participante da pesquisa de maneira direta.

Outra técnica utilizada na pesquisa foi a entrevista, sobre ela o autor Gil (2008, p.109) considera a entrevista uma das "técnicas de coleta de dados mais utilizada no âmbito das ciências sociais". O uso dessa técnica nesta pesquisa se justificou porque possibilitou ao pesquisador obter informações diretamente com o investigado, por meio de uma conversação esclarecendo pontos que talvez apenas analisando o documento físico não fosse possível. Também foram utilizadas atividades práticas para a coleta de dados, essas atividades foram elaboradas pelo professor/pesquisador e estavam relacionadas ao conteúdo de números inteiros. Essas atividades foram aplicadas junto aos alunos em período regular, nas aulas de matemática.

Quando essas atividades foram aplicadas os alunos já haviam estudado os números inteiros, pois este conteúdo é previsto no referencial curricular adotado pela rede municipal para ser trabalhado no primeiro e segundo bimestre. Por meio dessas atividades pode se obter os dados relacionados à aprendizagem dos alunos pesquisados, mas principalmente, os erros cometidos por eles, que são dados importantes para esse estudo. Os instrumentos de coleta foram utilizados de maneira a proteger a integridade física e moral dos alunos participantes da pesquisa, não sendo divulgados nomes ou imagens que não estivessem devidamente autorizadas e para a preservação da identidade dos alunos investigados, os seus nomes foram identificados por uma letra maiúscula do nosso alfabeto. As imagens apresentadas na pesquisa foram apenas das produções escritas de alguns alunos com o intuito de propiciar uma melhor análise dos erros cometidos por eles. 
Figueiredo, S. A.; Nascimento, E. A.

\section{DISCUSSÃO E ANÁLISE DOS DADOS COLETADOS}

A análise dos dados está organizada de acordo com a sequência cronológica como as atividades foram sendo desenvolvidas na sala pesquisada. Primeiramente foi aplicado o questionário para obtenção de dados pessoais e aprendizagem matemática cujos dados já foram descritos e na sequência foram aplicados dois testes que foram utilizados como forma de obtenção das produções escritas dos alunos em relação aos números inteiros, sendo esses testes aplicados em dias distintos.

O primeiro e o segundo teste eram compostos respectivamente por 05 e 06 questões. Neste estudo optamos por apresentar uma possível maneira para solucionar cada uma das questões presentes nos testes e assim identificarmos os erros cometidos pelos alunos investigados. Ressaltamos que a maneira como apresentaremos uma solução para cada questão pode não ser a única forma para solucioná-la visto que isso dependerá do processo como cada um interpreta o problema, pois nosso intuito é deixar claro qual é a resposta correta de cada questão.

Além disso, faremos uma análise de como os alunos resolveram estas questões identificando os erros cometidos e quais os possíveis obstáculos encontrados sob a ótica do que preconiza Brousseau. Para essa análise utilizaremos a tipologia de erros de Brousseau (2001, apud FRANCHI e HERNÁNDEZ, 2013, p. 66, tradução nossa) que considera que os professores geralmente classificam os erros como:

- Erro em um nível prático: quando o professor considera que são erros de cálculo.

- Erro na tarefa: quando o professor os atribui a descuidado.

- Erro da técnica: quando o professor critica a execução em um modo de operação conhecido.

- Erro da tecnologia: quando o professor critica a eleição da técnica.

- Erro do nível teórico: quando o professor incrimina os conhecimentos teóricos do aluno que servem de base para a tecnologia e as técnicas associadas.

Para a análise de erros dos alunos, nessa pesquisa optamos por categorizar essa tipologia de erros de Brousseau (2001) por considerarmos que facilitaria o agrupamento de obstáculos comuns presentes nas respostas dos alunos. Desta maneira, usaremos nesta pesquisa a seguinte categorização dos erros:

- E1: erro em um nível prático. 
- E2: erro na tarefa.

- E3: erro da técnica.

- E4: erro da tecnologia.

- E5: erro do nível teórico.

Como forma de facilitar a análise e a compreensão das produções escritas dos alunos optou por realizar separadamente os testes já referidos. Segue apenas uma análise do teste 01 trazendo o enunciado das questões 01,03 e 05 bem como uma possível maneira para solucioná-la. E as questões 02 e 04 seguiram o mesmo tipo de análise.

A primeira questão desse teste apresentava o seguinte enunciado:

Leia a manchete do Jornal o Estadão:

\section{Mais de 20 cidades em SC amanhecem com temperaturas abaixo de zero}

11 Julho 2018 | $10 \mathrm{~h} 21$

PORTO ALEGRE - O frio continua nos municípios situados na região da Serra em Santa Catarina. Na madrugada e amanhecer desta quarta-feira, 11, diversas cidades registraram temperaturas abaixo de $0^{\circ} \mathrm{C}$. De acordo com o meteorologista Leandro Puchalski, ao menos 23 municípios tiveram a manhã desta quarta-feira congelante, entre elas Urupema, que registrou $-3^{\circ} \mathrm{C}$, Curitibanos, com $-2,5^{\circ} \mathrm{C}$, Lages, com $-1,9^{\circ} \mathrm{C}$, e Otacílio Costa com $-1,6^{\circ} \mathrm{C}$.

Fonte: Luciano Nagel e Ana Paula Niederauer, O Estado de S. Paulo

A manchete do Jornal o Estado de São Paulo apresenta algumas das temperaturas de cidades de Santa Catarina como Urupema que registrou $-3^{\circ} \mathrm{C}$. A temperatura vai cair mais $-5^{\circ} \mathrm{C}$, então qual será a nova temperatura em Urupema?

Fonte: NASCIMENTO, 2019

Para solucionar esta questão era preciso compreender que, em se tratando de temperatura, quando afirma que ela "vai cair" significa que irá diminuir. De acordo com o comando, a nova temperatura que a questão solicitava era da cidade de Urupema que tinha, de acordo com o enunciado, uma temperatura de $-3^{\circ} \mathrm{C}$. Como ela vai cair $5^{\circ} \mathrm{C}$ significa que a cidade em questão ficará com uma nova temperatura de $-8^{\circ} \mathrm{C}$.

$\mathrm{Na}$ análise dos erros cometidos obtivemos 3 erros que podem ser categorizados como erros de cálculos visto que, analisando suas produções, notamos que os alunos escreveram corretamente a expressão, porém, erraram ao adicionar as duas temperaturas negativas. 
Figueiredo, S. A.; Nascimento, E. A.

Tabela 1 -Distribuição dos tipos de erros na questão 01 do teste 01

\begin{tabular}{c|c}
\hline Categoria & Quantidade de ocorrências \\
\hline E1 & 03 \\
\hline E2 & - \\
\hline E3 & - \\
\hline E4 & 04 \\
\hline E5 & 01 \\
\hline
\end{tabular}

Fonte: Elaborado pelo autor

A categoria E1 que envolve os erros relacionados em nível prático, ou seja, os erros de cálculos foram identificados nas respostas apresentadas pelos alunos G, I e P.

$\checkmark$ Resposta dada na entrevista pela aluna G: "Eu peguei a temperatura de Urupema e somei com a que vai cair e aí deu 7".

$\checkmark$ Resposta dada na entrevista pelo aluno I: "Vai ser zero, porque se está no 3 e vai cair mais 5 aí vai parar no zero.".

$\checkmark$ Resposta dada na entrevista pela aluna P: "Eu entendi assim, vai ser zero porque se a nova temperatura de Urupema é -3 e vai cair 5, então ela vai ficar zero.".

Os erros cometidos pelos G, I e P podem ser categorizados como erros de cálculos, visto que analisando suas produções notamos que eles escreveram corretamente a expressão, porém, erraram ao adicionar as duas temperaturas negativas.

Nas categorias E2 e E3 que trata respectivamente dos erros ligados ao descuido e na execução de um procedimento conhecido, não tivemos nenhum erro.

$\mathrm{Na}$ categoria E4 que se refere a erros da tecnologia, ou seja, os erros relacionados com a escolha incorreta da técnica, foram identificados 04 respostas erradas. Na categoria E5, que trata dos erros voltados com a falta de conhecimento teórico, tivemos apenas um erro cometido.

De acordo com erros dos alunos foi possível constatar que há erros matemáticos envolvendo a interpretação da questão e com as operações matemáticas. Analisando todas as respostas e os argumentos utilizados pelos alunos para justificá-las, verificou-se que os erros cometidos mostram que há vários obstáculos que os impedem ir ao encontro com o acerto.

Brousseau (2001) afirma que os professores tendem a tipificar esse erro em nível teórico; isso é devido ao fato de identificar tais erros como falha no conhecimento e 
acabam voltando a trabalhar sem um projeto educacional. Assim a maneira de abordar o erro é para este autor uma estratégia didática que tem suas vantagens, porém, caso o diagnóstico do professor esteja errado pode também provocar bloqueios nos alunos, isso porque a resolução dos alunos pode ter sido gerada de modo espontâneo, sem formalidades e se o professor aguardar apenas relações formais os alunos podem se sentirem desmotivados.

Brousseau (2001) sugere ainda que se procurem as causas dos erros em outros lugares que não só no conhecimento, visto que compreender como se deu a forma processual de desenvolvimento do problema pode trazer informações acerca de como os erros foram cometidos. Desta maneira, os erros encontrados nesta questão são de origem epistemológica, ou seja, estão intimamente ligados com a forma de aquisição do conhecimento.

Na sequência de nossa análise veremos o enunciado da questão 03 do teste 01 .

No mês passado, o extrato bancário de Carla indicou que ela tinha dinheiro em sua conta. Seu saldo bancário era de $\mathrm{R} \$ 109,00$. Este mês, o saldo bancário de Carla é de -R \$ 87,00. O que isto significa? E qual o valor gasto por ela do mês passado para este mês?

Fonte: NASCIMENTO, 2019

Para resolver esta questão era preciso compreender que a correntista do banco possuía um saldo positivo na conta bancária no valor de $\mathrm{R} \$ 109,00$ e, decorrido um mês, seu saldo passou a ser negativo, indicando um gasto maior do que havia na conta, ou seja, esse gasto superou o saldo da conta em $\mathrm{R} \$ 87,00$. Logo, para saber o valor gasto por ela, deve ser feito o seguinte cálculo.

\section{9,00 \\ $+87,00$ \\ 196, 00}

Então, o valor gasto por Carla foi de R\$196,00 e, como não tinha esse valor na conta, seu saldo bancário ficou negativo, o que significa dizer que ela está devendo o valor de $\mathrm{R} \$ 87,00$ ao banco.

Analisando as produções escritas dos alunos constatamos que 19 deles erraram essa questão, sendo que os erros mais comuns estão relacionados com as operações básicas da matemática e também em relação à interpretação do problema.

A tabela abaixo mostra a quantidade de erros encontrados na questão 03 em cada 
uma das cinco categorias de erros.

Tabela 2 - Distribuição dos tipos de erros na questão 03 do teste 01

\begin{tabular}{l|l}
\hline Categoria & Quantidade de ocorrências \\
\hline E1 & - \\
\hline E2 & - \\
\hline E3 & - \\
\hline E4 & 19 \\
\hline E5 & - \\
\hline
\end{tabular}

Fonte: NASCIMENTO, 2019

De acordo com a tabela acima é possível identificar que, para essa questão, todos os erros encontrados foram categorizados como erros na escolha da técnica, ou seja, erros relacionados com a escolha da técnica correta para efetuar e resolve-la. Verificou-se que os erros ocorreram devido à maneira como esses associaram o sinal negativo, embora alguns alunos tenham feito outros cálculos e/ou mesmo tenham errado em alguns deles.

Com base nas respostas dos alunos identificamos que os erros por eles cometidos se deram devido a dois aspectos: um relacionado com a escolha da operação para encontrar o valor gasto pela correntista do banco e o outro com a dificuldade na operação escolhida.

Os erros dos alunos foram categorizados como E4, que são aqueles relacionados com a escolha errada da técnica. Embora alguns alunos tenham errado nas operações matemáticas, não os classificamos na categoria de erros de cálculos por entendermos que a causa principal para o erro da questão foi a escolha errada da técnica, pois mesmo se tivessem feito corretamente os cálculos descritos em suas produções isso não implicaria na resposta correta da questão.

Analisando os erros dos alunos nessa questão percebemos que a maioria buscou resolver a questão subtraindo os saldos; esse erro ocorreu por imaginarem que o sinal de negativo próximo do saldo atual de Carla pudesse indicar que a operação a ser realizada fosse uma subtração entre os saldos.

Sobre a confusão com o negativo e a operação de subtração é comum encontrarmos erros relacionados a isso tornando relevante e necessário uma ampliação sobre a concepção das operações matemáticas, tendo em vista que os alunos são levados a associar o sinal de negativo com a operação de subtração e o sinal de positivo com a adição.

Os erros cometidos pelos alunos nessa questão são decorrentes de obstáculos didáticos e epistemológicos, como afirma Brousseau (1998). O primeiro por estar 
associado à forma como os alunos são ensinados quando estão conhecendo as operações com os números naturais, tornando-se um obstáculo o reconhecimento do sinal (-) que até então era usado como subtração de números e que, ao lidar com os inteiros, este passa a assumir um novo conceito representando um número negativo. Os obstáculos epistemológicos são decorrentes da própria confusão dos conceitos matemáticos.

Yamazaki, Sérgio e Yamazaki, Regiani (2011, p. 61) afirmam que:

\begin{abstract}
$\mathrm{Na}$ epistemologia de Bachelard, é preciso que todo obstáculo seja destruído, causando uma ruptura no pensamento dos estudantes. Só assim, é que um novo conhecimento (científico) poderá de fato ser construído. Sem a desestabilização, os indivíduos têm a impressão que compreenderam; às vezes isso acontece, mas não significa que houve aceitação da construção científica, que na maioria das situações, mostra-se incoerente com as impressões edificadas pela vida.
\end{abstract}

A questão 04 apresentava os números inteiros de uma forma contextualizada, usando informações em forma de gráficos relacionadas com o lucro e prejuízo de uma empresa. O objetivo era avaliar a capacidade dos alunos em identificar e comparar os números inteiros.Na sequência veremos o enunciado completo dessa questão e em seguida uma maneira de como resolvê-la.

A questão 05 do teste 01 era composta por um exemplo da aplicação dos números inteiros dessa vez com questões financeiras envolvendo créditos e débitos. A seguir temos o enunciado dessa questão e na sequência uma possível maneira de solucioná-la.

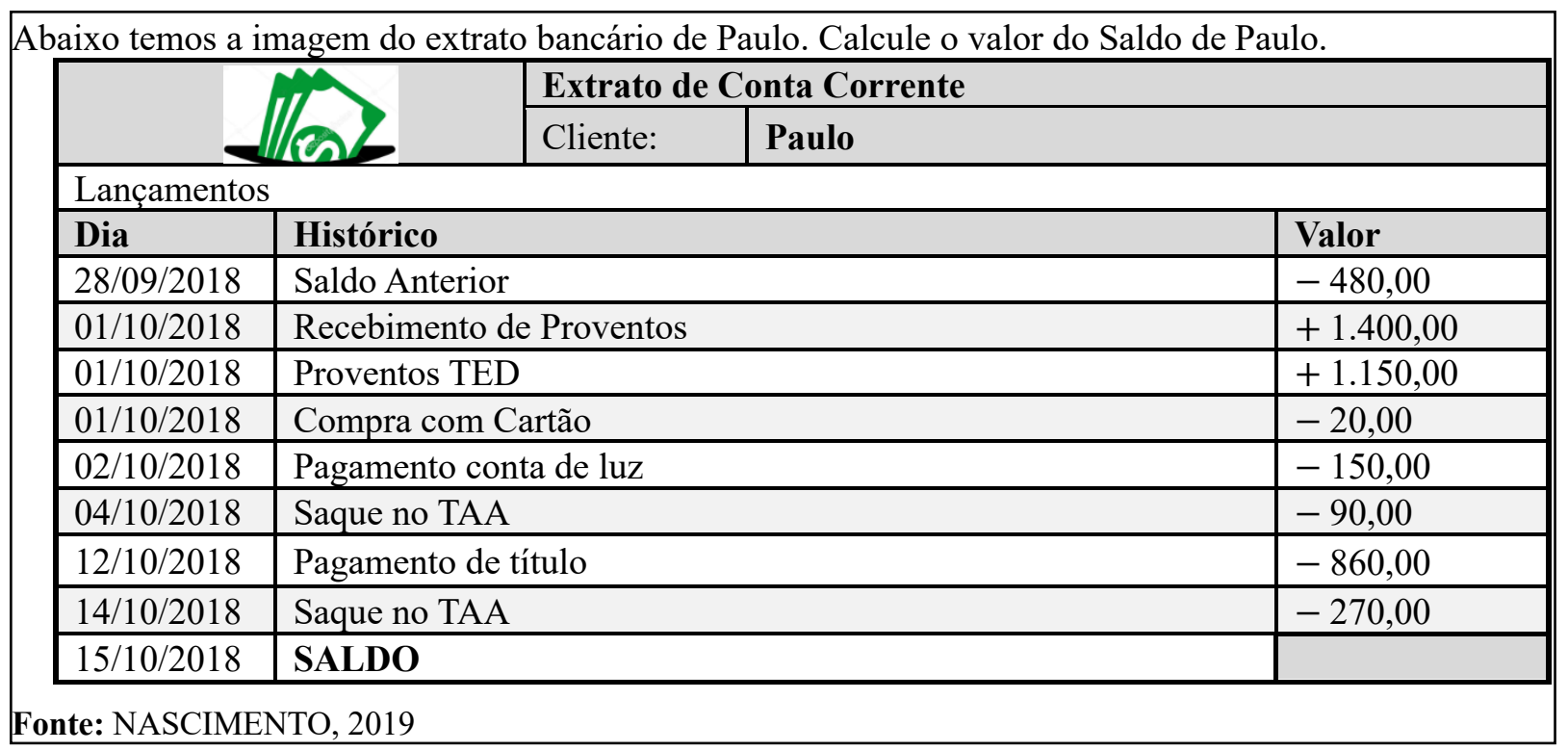

Uma maneira possível para solucionar esta questão era somar os saldos de débitos e créditos separadamente e em seguida realizar uma subtração entre os saldos mantendo o 
Figueiredo, S. A.; Nascimento, E. A.

sinal do maior saldo. Vejamos abaixo como isso pode ser realizado:

Débito da conta

$$
-480,00-20,00-150,00-90,00-860,00-270,00-1.870,00
$$

\section{Crédito da conta}

$$
+1.400,00+1.150,00+2.550,00
$$

Agora devemos subtrair os valores obtidos e manter o sinal do maior saldo encontrado que, neste caso, será positivo.

$$
+2.550,00-1.870,00+680,00
$$

Portanto, o saldo bancário de Paulo é de $+680,00$.

Analisando as respostas dos alunos para essa questão observamos um total de 12 erros. A tabela abaixo apresenta a distribuição desses erros em cada uma das categorias.

Tabela 3 - Distribuição dos tipos de erros na questão 05 do teste 01

\begin{tabular}{l|l}
\hline Categoria & Quantidade de ocorrências \\
\hline E1 & 07 \\
\hline E2 & - \\
\hline E3 & - \\
\hline E4 & - \\
\hline E5 & 05 \\
\hline
\end{tabular}

Fonte: Nascimento, 2019

Conforme apresentado na tabela acima, foram encontradas 07 produções dos alunos com erros relacionados ao cálculo nas operações envolvendo os números inteiros e 06 produções com erros que foram categorizados como E5, ou seja, erro em nível teórico que são aqueles que ocorrem por falta de conhecimento teórico para solucionar a questão.

Com base nas produções dos alunos notamos que os erros cometidos pela maioria deles foi ter somado todos os valores apresentados no extrato bancário ignorando os sinais de (+) e (-) dos números. Esse fato sugere que os alunos ainda não reconhecem um número negativo e isso mostra que ainda não possuem conhecimento teórico suficiente que permita realizar cálculos matemáticos que os envolva. Os erros encontrados nessa questão e que se encontram na categoria de erros E5 mostram a dificuldade no reconhecimento do número negativo.

Ressalta-se também que, embora houvesse alguns erros dos alunos na operação matemática de adição, optamos por não categorizá-los como erros em nível prático por entender que esse não foi o motivo principal para que não pudessem ter solucionado a 
questão, visto que mesmo que os alunos tivessem realizado seus cálculos corretamente não a solucionaria porque demandava outros cálculos. A análise do teste 02 foi feita do mesmo modo como fizemos no teste $01 \mathrm{em}$ que tratamos os enunciados de cada questão e apresentamos uma possível maneira de solucioná-la e, na sequência, apresentamos os erros dos alunos pesquisados para cada uma dessas questões juntamente com trechos das entrevistas em que explicam a maneira como a resolveram.

Os erros matemáticos cometidos pelos alunos nesse teste também foram categorizados conforme a tipologia de erros de Brousseau (2001), ou seja, categoria E1: erros em nível prático, aqueles relacionados com problemas no cálculo, categoria E2: erros na tarefa, aqueles relacionados com descuido, categoria E3: erros da técnica, aqueles relacionados com problemas no modo de operação conhecido, categoria E4: erros da tecnologia, aqueles relacionados com a escolha incorreta da técnica e a categoria E5 que são os erros do nível teórico, aqueles relacionados com a falta de conhecimento teórico.

Para fins de ilustração, segue apenas uma análise do teste 02 trazendo o enunciado da questão 01, bem como uma possível maneira para solucioná-la. As demais questões do teste 2 seguiram o mesmo tipo de análise.

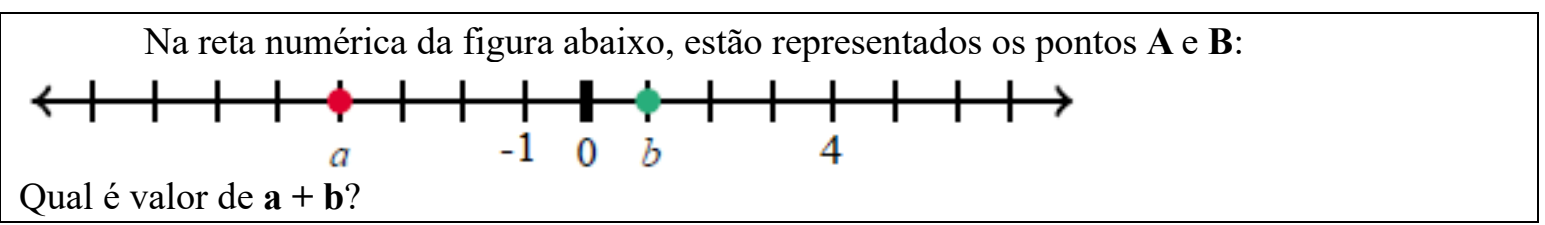

Fonte: Adaptado do site khan Academy, 20192

O objetivo dessa questão era identificar a capacidade dos alunos em localizar os números inteiros na reta numérica e também se eram capazes de efetuar o cálculo de adição entre dois números inteiros.

Para resolver essa questão era preciso identificar os valores de "a" e "b" na reta numérica e depois somá-los. Como veremos abaixo:

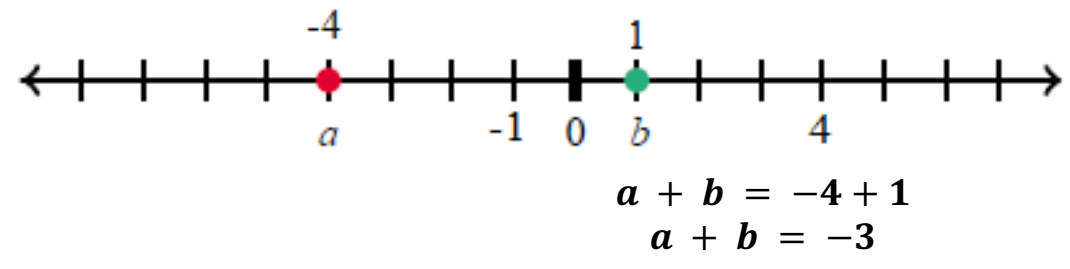

\footnotetext{
${ }^{2}$ A Khan Academy é uma organização educacional sem fins lucrativos, que oferece exercícios e vídeos instrucionais em diversas áreas do conhecimento de maneira gratuita a todos.
} 
Com base nas produções dos alunos foi possível identificar que 11 deles erraram essa questão. A tabela que veremos a seguir mostra como esses erros foram distribuídos na categoria de erros baseada na tipologia de Brousseau (2001).

Tabela 4 - Distribuição dos tipos de erros na questão 01 do teste 02

\begin{tabular}{l|l}
\hline Categoria & Quantidade de ocorrências \\
\hline E1 & - \\
\hline E2 & - \\
\hline E3 & - \\
\hline E4 & - \\
\hline E5 & 11 \\
\hline
\end{tabular}

Fonte: NASCIMENTO, 2019

Através da análise de erros foi possível identificar que todos os erros observados nessa primeira questão estavam ligados com a adição de números inteiros, uma vez que todos os alunos foram capazes de identificá-los na reta numérica. Com a análise das produções e os relatos dos alunos identificamos que esses erros fazem parte da categoria de erros E5, pois tais erros se deram pela falta de conhecimento teórico para operar com números inteiros.

De acordo com os erros observados na questão 01 notamos que todos estavam relacionados com a adição entre números inteiros. A dificuldade apresentada pelos alunos pode estar associada com o fato de que a adição que estavam acostumados a realizar era sempre envolvendo números naturais, tornando-se a adição de números inteiros um obstáculo. Quando os alunos resolveram a adição de dois números inteiros como se eles fossem dois números naturais mostraram a dificuldade de ruptura do conhecimento que trazem diante do novo conhecimento.

Bachelard (1996) afirma que, no ato de conhecer, o aprendiz irá buscar familiaridade com aquilo que já conhece tornando o novo conhecimento um obstáculo na aprendizagem. Para Brousseau (2008), o novo conhecimento passa a se tornar um obstáculo epistemológico quando os alunos cometem erros e esses não são devidos à ignorância ou falta de conhecimento, mas a um conhecimento que até então era verdadeiro e que num novo contexto se apresenta falso.

Os erros encontrados e analisados na questão 01 mostram que os alunos têm o conhecimento para resolverem a adição com números naturais, porém, ainda não reconhecem a adição com números inteiros. 
Baseado na tipologia de Brousseau (2001) na investigação observamos erros em operações básicas da Matemática que foram a causa principal para o erro das atividades estes erros classificamos na categoria E1, que segundo o autor, afirma que esses erros são de nível prático ou erros de cálculo e ocorreram com mais frequência elevando o número de erros nas questões.

Também apuramos nessa investigação, os erros cometidos pelos alunos por falta de atenção e descuido; esse tipo de erro foi encontrado nas questões dos dois testes aplicados. $\mathrm{Na}$ tipologia de erros de Brousseau (2001) eles foram classificados como erro na tarefa e foram categorizados nessa pesquisa como E2. Os erros dessa categoria ocorreram principalmente nas questões do teste 02 em atividades envolvendo a localização e comparação dos números inteiros. Já na categorização classificados como E3 (Erros técnicos) descritos na tipologia de Brousseau (2001) como aqueles que são criticados pelos professores na execução de um procedimento conhecido, não foi detectado em nossa análise nenhum tipo de erro que pudesse ser enquadrado nessa categoria.

Um erro também encontrado nas respostas dos alunos nessa investigação foram os erros de tecnologia pertencentes à categoria de erros E4 e fazem parte desse tipo de erro aqueles cometidos pela escolha errada do método de resolução. A maior incidência desse tipo de erro ocorreu na questão 03 do teste 01 , questão essa que avaliava a capacidade dos alunos em efetuar a adição de saldos (débitos e créditos) bancários.

A última categoria de erros baseada na tipologia de Brousseau (2001) foi a categoria E5 que são os erros de nível teórico, ou seja, aqueles relacionados com a falta de conhecimento teórico do aluno. A ocorrência desse tipo de erro foi constatada nos dois testes aplicados com maior incidência nas questões do teste 02 . Assim esta pesquisa propos analisar os erros cometidos por alunos do $7^{\circ}$ Ano do Ensino Fundamental em questões relacionadas com os números inteiros e classificá-los de acordo com a tipologia de Brousseau (2001).

\section{CONSIDERAÇÕES FINAIS}

Através da aplicação de dois testes e entrevistas com os alunos foi possível levantar os seus erros com relação aos números inteiros e assim identificar os obstáculos didáticos que prejudicam suas conpreenções. Para essa pesquisa, saber como os alunos pensam ao 
realizar uma questão foi fundamental, uma vez que possibilitou identificarmos as barreiras que os alunos precisam transpor para atingir uma aprendizagem de qualidade.

A análise de erros empregada nessa pesquisa possibilitou, compreender como os erros podem ser utilizados para melhorar tanto o ensino quanto a aprendizagem. Os erros sempre foram vistos como algo negativo dentro do ensino-aprendizagem e que evitá-los sempre foi o caminho percorrido, mas também é fato que muitas vezes eles são inevitáveis.

Dentro do processo de ensino-aprendizagem os erros não podem ser controlados e nem estimulados, mas podem ser investigados pelos professores e esses não têm controle sobre os erros dos alunos e nem devem puni-los por tê-los cometidos, porque esses erros representam aprendizagens não bem-sucedidas e que precisam de intervenções pedagógicas. No entanto, não estamos afirmando que os erros sejam pretendidos dentro do ensino, pelo contrário, queremos compreendê-los para promover ações que possa ajudar o aluno a superá-los.

A análise de erros pode ser utilizada como estratégia metodológica de ensino e aprendizagem porque sua utilização traz contribuições relevantes para ambos os processos, seja como instrumento capaz de identificar os erros e os obstáculos dos alunos na aprendizagem matemática ou mesmo um instrumento de auto avaliação. Através dela o professor ou pesquisador poderá diagnosticar os erros dos alunos, sobretudo como eles ocorrem e assim compreender o que falta para que os alunos superem as falhas na aprendizagem matemática.

Destacamos alguns aspectos importantes dessa pesquisa que foram obtidos por meio da análise de erros, dentre esses estão os erros observados nas produções escritas dos alunos relacionados com as operações básicas da Matemática (ROSSATO, 2014). Como já vimos nos documentos oficiais de ensino, as operações básicas da Matemática são introduzidas no Ensino Fundamental inicial e são aprofundadas gradativamente no decorrer desse nível de ensino. Assim, quando o aluno ingressa no $7^{\circ}$ ano traz consigo um conhecimento significativo acerca dessas operações e imaginávamos que elas já não pudessem representar obstáculos à aprendizagem.

Essa pesquisa trouxe como resultados significativos não somente a identificação dos erros e como eles são produzidos pelos alunos, mas também mostrou que a análise de erros pode servir como um instrumento de auto avaliação para os alunos. Isso ficou bem 
claro dentro da pesquisa, principalmente nos relatos de vários alunos quando tentavam explicar como desenvolveu as questões, ou seja, eles, ao reverem suas respostas, identificaram seus erros e algumas vezes buscaram corrigi-los oralmente.

A análise dos erros dos alunos mostrou que esses ocorrem por diversos motivos, mas somente identificá-los e saber quais os fatores que os geraram não é o suficiente para superá-los, sendo necessário um esforço conjunto entre professor e aluno na busca de ações que ajudem a transpor esses obstáculos. Através dela o professor ou pesquisador poderá diagnosticar os erros dos alunos, sobretudo como eles ocorrem e assim compreender o que falta para que os alunos superem as falhas na aprendizagem matemática. Como aborte teórico para nortear a classificação dos erros encontrados nessa pesquisa envolvendo os números inteiros foram utilizadas as teorias do epistemólogo francês Guy Brousseau e sua tipologia de erro.

Por fim, concluimos que a análise de erros cometidos pelos alunos tem muito a contribuir para o ensino e a aprendizagem, seja utilizando-a como método ou como autoavaliação cuja pontencialidade nos pemite afirmar que o erro passa a ser mais um instrumento eficaz para o ensino e a aprendizagem.

\section{REFERENCIAS}

BACHELARD, Gaston. Formação do Espírito Científico. Rio de Janeiro: Contraponto, 1996.

BORASI, R. Using errors as springboards for the learning of mathematics: an introduction. Focus on Learning Problems in Mathematics. v. 7, n.3-4, p.1-14, 1985.

BRASIL. Base Nacional Comum Curricular: Educação Infantil e Ensino

Fundamental. Brasília: MEC/Secretaria de Educação Básica, 2017.

. Lei no . 9.394, de 20 de dezembro de 1996. Lei de Diretrizes e Bases da Educação Nacional. Brasília. DF, 1996.

BROUSSEAU, Guy. Introdução ao estudo das situações didáticas: conteúdos e métodos de ensino. 1. ed. São Paulo: Ática, 2008.

. Les erreurs des élèves en mathématiques : Etude dans le cadre de la théorie des situations didactiques (p.5-30); Petit $\mathrm{x}$; $\mathrm{n}^{\circ}$ 57; IREM de Grenoble ; Université Joseph Fourier Grenoble, 2001.

. Les obstacles épistémologiques et les problèmes en mathématiques.

Recherches em Didactique des Mathématiques,v.4, n.2, p. 165-198, 1983. 
COSTA, José Roberto. Desenvolvimento profissional de professores que lecionam matemática no Ensino Fundamental: possibilidades a partir da reflexão sobre os erros dos alunos. 2014. 258f. Tese (Doutorado em Educação para a Ciência e a Matemática), Universidade Estadual de Maringá, Maringá, 2014.

COSTA, Regiane Quezia Gomes da. Análise da prova da primeira fase da OBMEP como subsídio para orientar a prática docente. 2015. 214f. Dissertação (Mestrado Profissional em Matemática em Rede Nacional - PROFMAT), Universidade de Brasília, Brasília, 2015.

CRESWELL, John W. Projeto de pesquisa: métodos qualitativos, quantitativos e mistos. 2. ed. Porto Alegre: Artmed, 2007.

CRESWELL, John W.; CLARK, Vicki L. Pesquisa de métodos mistos. Porto Alegre: Penso, 2007.

CURY, Helena Noronha. Análise de erros. In: ENCONTRO NACIONAL DE EDUCAÇÃO MATEMÁTICA, 2010, Salvador. Anais... Salvador: SBEM, 2010, p. 02.

Análise de erros: o que podemos aprender com as respostas dos alunos. 2. ed. Belo Horizonte: Autêntica, 2017. 1990. . Ação e tentativas de superação. Porto Alegre: PUCRS, Instituto de Matemática,

CURY, H. N.; KONZEN, B. Uma aplicação de jogos na análise de erros em educação matemática. REVEMAT-Revista Eletrônica de Educação Matemática.v.2.6, p.107-117, 2007.

FRANCHI, L. \& HERNÁNDEZ, A. I. Topología de errores en el área de geometría plana. Educere, Investigación. Arbitrada, 24, 63-71. 2004.

HAUSER, Suely Domingues Romero. A transição da $4^{\mathbf{a}}$ para a $5^{\text {a }}$ série do Ensino fundamental: uma revisão bibliográfica, 2007. $62 \mathrm{f}$. Dissertação. Mestrado em Psicologia da Educação - Pontifícia Universidade Católica de São Paulo, 2007.

MATO GROSSO DO SUL. Secretaria de Estado de Educação (SED/MS). Referencial Curricular da Rede Estadual de Ensino de Mato Grosso do Sul Ensino Fundamental. Campo Grande, MS, 2012.

PINTO, N. B. O erro como estratégia didática: Estudo do erro no ensino da Matemática elementar. 2. ed. Campinas: Papirus, 2000.

ROSSATO, Sabrina Londero da Silva. Análise de erros na divisão de números decimais por alunos do $6^{\circ}$ ano do Ensino Fundamental. 2014. 111f. Dissertação (Mestrado em Ensino de Física e de Matemática), Centro Universitário Franciscano, Santa Maria, 2013.

TORRE, Saturnino de La. Aprender com os erros: o erro como estratégia de mudança. Tradução Ernani Rosa. Porto Alegre: Artmed, 2007.

VAZ, Rafael Filipe Novoa. Metodologia didática de análise de soluções aplicada no 
ensino de frações. 2013. 94f. Dissertação (Mestrado em Ensino de Matemática), Universidade Federal do Rio de Janeiro, Rio de Janeiro, 2013.

YAMAZAKI, Sérgio Choiti; YAMAZAKI, Regiani Magalhães de Oliveira. Pressupostos bachelardianos em sala de aula. In: GONÇALVES, A. V.; PINHEIRO, A. S.; FERRO, M. E. (Orgs.). Estágio Supervisionado e Práticas Educativas. Dourados/MS: Editora UEMS, p.49-74. 2011.

Submetido em 07 de maio de 2020. Aprovado em 21 de maio de 2021. 